\title{
BetaHPV E6 and E7 colocalize with NuMa in dividing keratinocytes
}

\section{Oswald, Evelyn}

$2019-10$

Oswald , E, Kirschberg , M , Aubin , F , Alonso , A, Hufbauer, M , Akguel , B \& Auvinen , E 2019 , ' BetaHPV E6 and E7 colocalize with NuMa in dividing keratinocytes ', Virus Genes, vol. 55 , no. 5 , pp. 600-609 . https://doi.org/10.1007/s11262-019-01685-9

http://hdl.handle.net/10138/320952

https://doi.org/10.1007/s11262-019-01685-9

publishedVersion

Downloaded from Helda, University of Helsinki institutional repository.

This is an electronic reprint of the original article.

This reprint may differ from the original in pagination and typographic detail.

Please cite the original version. 


\title{
BetaHPV E6 and E7 colocalize with NuMa in dividing keratinocytes
}

\author{
Evelyn Oswald ${ }^{1} \cdot$ Matthias Kirschberg $^{2} \cdot$ François Aubin $^{3} \cdot$ Angel Alonso $^{1} \cdot$ Martin Hufbauer $^{2} \cdot$ Baki Akgül $^{2}$ (1) . \\ Eeva Auvinen ${ }^{4}$
}

Received: 19 March 2019 / Accepted: 2 July 2019 / Published online: 9 July 2019

(c) Springer Science+Business Media, LLC, part of Springer Nature 2019

\begin{abstract}
Human papillomaviruses (HPVs) of genus betapapillomavirus (betaHPV) are implicated in skin carcinogenesis, but their exact role in keratinocyte transformation is poorly understood. We show an interaction of HPV5 and HPV8 oncoproteins E6 and E7 with the nuclear mitotic apparatus protein 1 (NuMA). Binding of E6 or E7 to NuMA induces little aneuploidy, cell cycle alterations, or aberrant centrosomes. Intracellular localization of NuMA is not altered by E6 and E7 expression in 2D cultures. However, the localization profile is predominantly cytoplasmic in 3D organotypic skin models. Both viral proteins colocalize with NuMA in interphase cells, while only E7 colocalizes with NuMA in mitotic cells. Intriguingly, a small subset of cells shows E7 at only one spindle pole, whereas NuMA is present at both poles. This dissimilar distribution of E7 at the spindle poles may alter cell differentiation, which may in turn be relevant for betaHPV-induced skin carcinogenesis.
\end{abstract}

Keywords Human papillomavirus · Betapapillomavirus · E6E7 oncoproteins $\cdot$ Nuclear mitotic apparatus protein 1

\section{Introduction}

A role for human papillomaviruses (HPVs) of genus betapapillomavirus (betaHPV) in the development of nonmelanoma skin cancer among immunosuppressed and immunocompetent individuals has been proposed for decades. The oncogenic potential of betaHPV in skin carcinogenesis was originally identified in patients suffering from the rare inherited disease epidermodysplasia verruciformis (EV),

Edited by Hartmut Hengel.

Electronic supplementary material The online version of this article (https://doi.org/10.1007/s11262-019-01685-9) contains supplementary material, which is available to authorized users.

Evelyn Oswald and Matthias Kirschberg contributed equally.

Baki Akgül

baki.akguel@uk-koeln.de

1 German Cancer Research Center, Heidelberg, Germany

2 Institute of Virology, University of Cologne, Faculty of Medicine and University Hospital of Cologne, Fürst-Pückler-Str.56, 50935 Cologne, Germany

3 Department of Dermatology, Université de Franche-Comté, Besançon, France

4 University of Helsinki and Helsinki University Hospital Laboratory, Helsinki, Finland who have an increased susceptibility to betaHPV infections. However, betaHPV can also be found in skin cancers of non-EV patients (reviewed in [1-3]). Recently, a prospective epidemiological study provided compelling evidence that betaHPV diversity and viral loads in the skin are associated with squamous cell carcinogenesis [4]. Further support for an etiologic role arose from the observation that betaHPV is frequently detected in actinic keratoses, which are premalignant lesions of the skin [5]. Curiously, despite frequent detection of betaHPV DNA in premalignant lesions of immunocompetent patients, viral sequences are rarely found in skin tumors in these patients, pointing towards a hit-and-run mechanism by betaHPV in the carcinogenic process $[6,7]$.

To prove the oncogenic potential of betaHPV early proteins in vivo, HPV8 transgenic mice were generated, in which the expression of the complete early genome region (CER) is under the control of the human keratin-14 promoter (K14-HPV8-CER). These animals develop papillomas, partially along with moderate to severe dysplasia and squamous cell carcinoma (SCC) $[8,9]$.

Mechanistically, HPV5 and HPV8 E7 positive cells display hyperproliferation and are positive for both cyclin $\mathrm{E}$ and p16INK4a, indicating that E7 is able to overcome p16INK4a-induced cell cycle arrest [10]. BetaHPV E7 oncoproteins bind $\mathrm{pRb}$ with lower affinity than high-risk 
alphaHPV [11], and this binding is accompanied by degradation of pRb [12]. In particular, the E7 oncoprotein of HPV8 proved to be the major mediator of keratinocyte invasion in 3D organotypic skin cultures. E7 positive cells lose their polarity and migrate downwards into the extracellular matrix $(\mathrm{ECM})$, concomitant with upregulation of matrix metalloproteases (MMP) [13]. In addition, E7-mediated invasion is directed by overexpression of integrin $\alpha 3 \beta 1$ and interaction of E7 positive cells with fibronectin in the ECM [14].

It has previously been shown that HPV6, HPV11, and HPV16 E7 proteins bind to nuclear mitotic apparatus protein 1 (NuMA) leading to the introduction of mitotic errors and aneuploidy [15]. NuMA is indispensable in organizing microtubules at centrosomes and in chromosome alignment during mitosis [16-18]. Furthermore, post-mitotic nuclear reassembly is dependent on NuMA, and NuMA is also a crucial structural component of the nuclear matrix during interphase (reviewed in [19]). Another key function of NuMA is the control of cell polarity, which is important for asymmetric division of basal epithelial cells [20,21].

In search for cellular interaction partners of HPV 5 and HPV8 E6 and E7, we identified NuMA as a binding partner for these viral proteins and describe relevance of this association for keratinocyte homeostasis.

\section{Materials and methods}

\section{Cell culture}

$293 \mathrm{~T}$ and COS-7 cells were cultured in DMEM supplemented with $10 \%$ FCS, penicillin, and streptomycin. COS-7 cells were used in immunofluorescence experiments because they are easy to transfect. Primary human keratinocytes (PHKs) were cultured in KGM-2 Medium (Promocell, Heidelberg, Germany). Phoenix cells were cultured as previously described [22] for the generation of recombinant retroviruses.

\section{Plasmids and transfections}

Retroviral constructs for the expression of HPV5 and HPV8 E6, E7, E6E7 and HPV16 E6E7 were generated using the pLXSN vector. These constructs were transfected into Phoenix cells, and retroviruses were subsequently isolated and used to transduce PHK cells as previously described [22]. HPV5 E7 mutants I2P, $\Delta 26-29$, E31G, R66E, and $\Delta 79-83$ cloned into pcDNA3.1(-) were obtained from Dr. Ramon Garcia-Escudero (CIEMAT, Madrid, Spain) and then further subcloned into a pGEX4T3 vector for the expression of N-terminal GST fusion proteins. Expression constructs pCMV-SPORT-3xFLAG-E6 or -E7 of HPV5 or HPV8 were generated for expression of fusion proteins coding for triple flag-tagged viral proteins [23] to be used in immunoprecipitation experiments. HPV5 and HPV8 E6 and E7 genes were subcloned into pCMV to express fusion proteins with the AU1 epitope tag for immunofluorescence analyses.

\section{Yeast two-hybrid system}

In order to identify cellular proteins binding to HPV5 E6 or E7 oncogenes, the Matchmaker two-hybrid system was used together with a cDNA library from the HaCaT human keratinocyte cell line (Clontech, Saint-Germain-en-Laye, France). Either E6 or E7 was used as a bait. Identification of binding proteins was performed by MALDI-TOF as previously described [24].

\section{GST pulldown experiments}

Preparation of GST fusion proteins and GST pulldown experiments were performed as previously described [23]. In these experiments both wild-type (wt) HPV 5 and HPV8 E7 as well as the HPV5 E7 mutants I2P, $\Delta 26-29$, E31G, R66E, I67R, and $\Delta 79-83$ were used.

\section{Immunoblotting, immunoprecipitation, and confocal microscopy}

Primary antibodies used in immunoblotting, immunoprecipitation, and immunofluorescence are described in Supplementary Table 1. Proteins were separated by SDS-PAGE, transferred to PVDF membranes and immunoblotted with the corresponding antibodies, and detection was carried out using ECL. Immunoprecipitation of flag-tagged E6 or E7 proteins was performed as previously described [23]. For immunofluorescence experiments, cells were grown on coverslips and subsequently transfected with expression constructs, fixed with $3 \%$ paraformaldehyde, washed, and incubated with primary antibodies. Secondary antibodies were labeled with Alexa488 or Alexa594 (Invitrogen, Carlsbad, CA). Images were generated using a Zeiss LSM 700 or a Leica TCS SP microscope.

\section{Cell cycle and DNA content analysis}

Transduced and control PHK cells were treated for $24 \mathrm{~h}$ with nocodazol, fixed, stained with propidium iodide, and analyzed for DNA content by FACS. The experiments were repeated twice, each time with two biological replicates. FACS analyses were performed on a FACSCalibur flow cytometer (BD Biosciences, San Jose, CA) using fixed cells. The data were analyzed using CellQuest (BD Biosciences) as well as FlowJo (Tree Star, Ashland, OR) as described elsewhere [25]. Transduced as well as control PHK cells were exposed to BrdU for 45 min, fixed and stained using fluorescein-labeled BrdU 
antibodies (Supplementary Table 1). BrdU incorporation was measured using FACS analysis.

\section{Centrosome number quantification}

In order to quantify centrosome numbers, PHK were transduced with retroviruses, fixed in PFA and then stained with antibodies targeting pericentrin. DNA was visualized by DAPI staining. The experiment was repeated twice, and the centrosome numbers were calculated in a minimum of 200 cells per experiment with comparable results.

\section{UV irradiation of the K14-HPV8-CER and FVB/n wt mice}

Mouse lines used in this study included FVB/n wt (Charles River Laboratories, Sulzfeld, Germany) and the transgenic hemizygous FVB/N line K14-HPV8-CER [8]. UV irradiation protocols were approved by the governmental animal care office North-Rhine-Westphalia (Leibnizstraße 10, 45659 Recklinghausen, Protocol No. 8.87-50.10.35.08.163) and were in accordance with the German Animal Welfare Act as well as the German Regulation for the protection of animals used for experimental purposes. For UV treatment, age (5 weeks) and sex-matched mice were shaved and irradiated once with $10 \mathrm{~J} / \mathrm{cm}^{2} \mathrm{UVA}$ and $1 \mathrm{~J} / \mathrm{cm}^{2} \mathrm{UVB}$ on a $4 \mathrm{~cm}^{2}$ sized dorsal caudal area. All offspring were macroscopically examined for the presence of skin lesions on day 24 after UV treatment. On day 24 after UV irradiation the animals were sacrificed and samples of the irradiated skin were collected, fixed, and subsequently embedded in paraffin.

\section{Sections of EV skin lesions and organotypic cultures}

Human EV biopsy material from archival paraffin blocks taken during routine surgical excision (for detailed information see [26]) was used in this study. Ethical approval for the use of human samples was obtained from the Ethics Committee of the Medical University of Warsaw.

The generation of organotypic skin cultures of keratinocytes expressing HPV5, HPV8, or HPV16 E7 was based on a deepidermalized human dermis serving as the dermal equivalent, which was then repopulated with PHKs. These 3D cultures were grown for 14 days at the air-liquid interphase, followed by fixing and embedding in paraffin [10].

\section{Results}

\section{Identification and validation of NuMA among binding partners of betaHPV E6 and E7}

In order to identify putative interaction partners of E6 and E7 of HPV5, yeast two-hybrid screens were performed. Among the putative E6 interaction partners we identified NuMA. Subsequent in vitro GST pulldown experiments confirmed the interaction between NuMA and E6 as well as E7 of HPV5 and HPV8 (Fig. 1a). Furthermore, 293T cells were transfected separately with pCMV-SPORT-3xFLAG-E6 or -E7 expression constructs coding for flag-tagged HPV5 and HPV8 E6 or E7 proteins. Immunoprecipitation with extracts from transfected cells was then performed with anti-flag antibodies. Again, NuMA coprecipitated with E6 and E7 proteins of both HPV5 and HPV8, and E6 binding was consistently shown to be stronger than E7 binding (Fig. 1b).

\section{NuMA binding is independent of the $\mathrm{pRb}$ binding site of E7}

Binding of HPV16 E7 to NuMA is known to be dependent on the $\mathrm{pRb}$ binding domain of E7 [15]. In order to analyze whether betaHPV might share this property we performed binding experiments using N-terminal GST fusion constructs of wt HPV5 E7 as well as the E7 variant $\Delta 26-29$, known to be defective in respect to $\mathrm{pRb}$ binding [27] and additional constructs mutated at positions I2P (abrogating hydrophobicity), E31G, R66E, I67R (which all changed the charged at their respective positions) or $\Delta 79-83$ (deletion of the zinc finger domain [28]). The GST pulldown experiments showed no significant reduction in NuMA binding by any of the tested E7 mutants (Fig. 1c). We therefore concluded that regions outside the $\mathrm{pRb}$ binding and zinc finger domain are required for NuMA binding by HPV5 E7.

\section{Expression of NuMA in betaHPV-positive skin}

In order to characterize NuMA expression in betaHPV-positive differentiating epithelia, we first studied the staining pattern of NuMA in the skin of K14-HPV8-CER transgenic mice. These mice develop skin tumors 3 weeks following UV exposure, whereas the FVB/n wt mice heal from UVinduced hyperplasia $[9,29]$. In FVB/n wt skin, which healed from UV-induced hyperplasia, NuMA is mainly expressed in the hair follicles, with weak staining of the interfollicular epidermis (Fig. 2a). In skin tumors of K14-HPV8CER mice, elevated expression of NuMA throughout the epithelium was observed. In healthy human skin, nuclear NuMA appeared to be evenly distributed throughout the 
Fig. 1 HPV5 and HPV8 E6 and E7 bind to NuMA. a Lysates of 293T cells were subjected to GST pulldown using HPV5 and HPV8 E6 or E7 GST fusion proteins. One-tenth of the extract was used as loading control. Antibodies against GST and NuMA were used in immunoblotting. b 293T cells were transfected with expression constructs coding for flag-tagged HPV5 and HPV8 E6 and E7 proteins. Cell lysates were analyzed by immunoprecipitation and immunoblotting using antibodies against the flag epitope or NuMA *E7 multimer. c NuMA binding by wild-type and mutant HPV5 E7 proteins. 293T cell lysates were subjected to GST pulldown using wild-type or mutant GST E7 fusion proteins. Immunoblotting was performed with antibodies against GST or NuMA

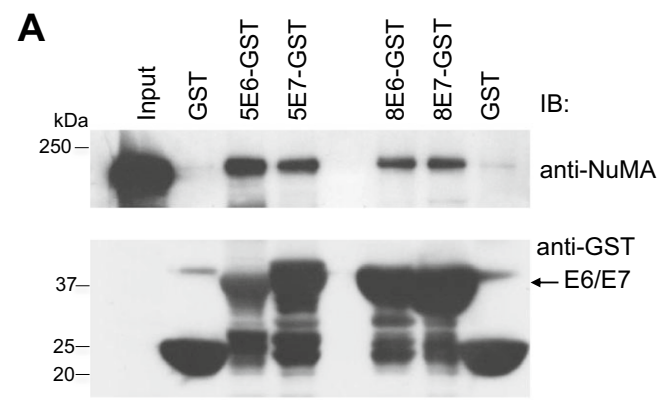

B
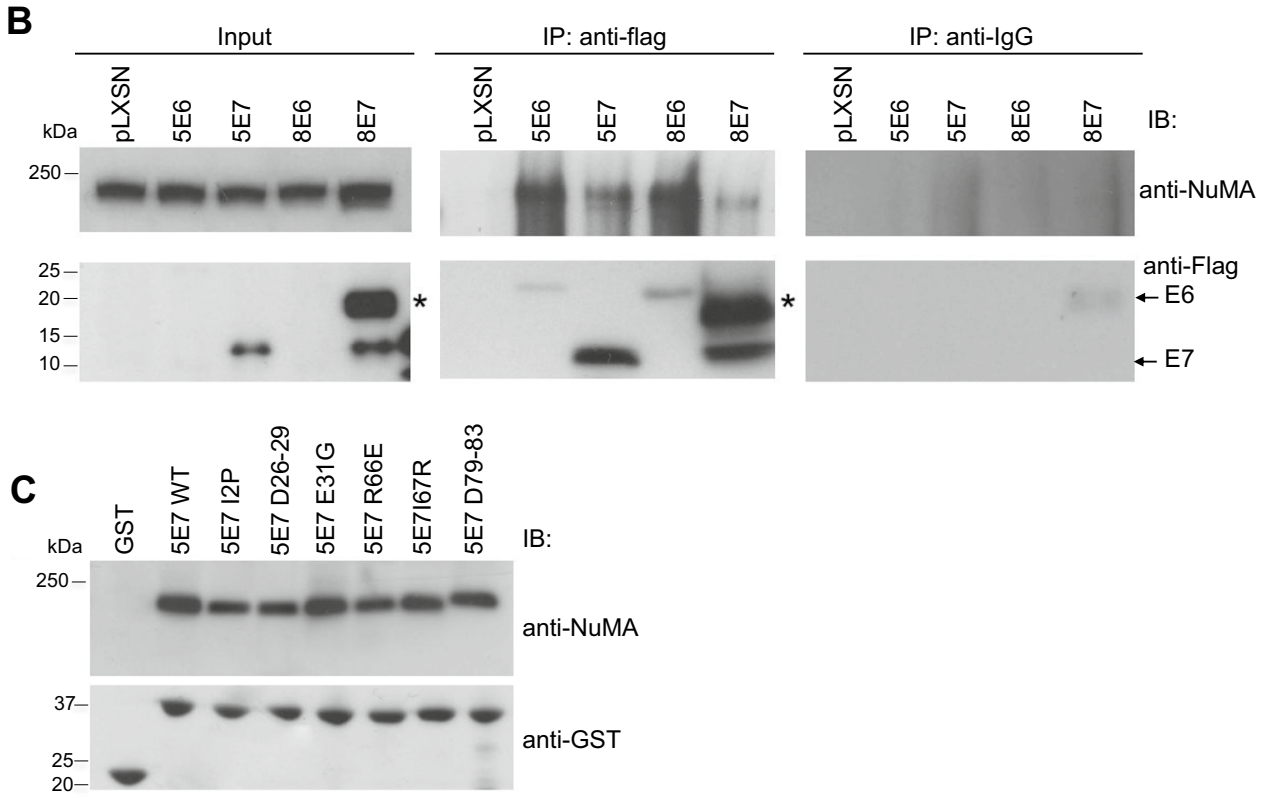

basal cell layer with decreasing staining intensity toward the skin surface. In skin SCC sections from EV patients we detected different staining patterns. For instance, in section EV-a, NuMA is mainly nuclear but also cytoplasmic and restricted to the suprabasal cell layers. Unexpectedly, in the skin SCC section EV-b NuMA has a mainly cytoplasmic staining profile (Fig. 2b). Interestingly, in organotypic skin cultures of control keratinocytes, NuMA is exclusively cytoplasmic. The same holds true for the HPV8 E7 skin culture with stronger staining intensity in the suprabasal cell layers (Fig. 2c).

\section{E6 and E7 and NuMA colocalize in interphase}

We next studied the subcellular localization of E6 or E7 and NuMA by means of immunofluorescence and laser confocal microscopy. Cells were transfected with expression constructs coding for AU1-tagged E6 or E7 fusion proteins of HPV5 and HPV8. The cells were then fixed and stained with a specific antibody targeting AU1. Nuclear NuMA expression in interphase COS-7 cells was shown, which proved not to be altered by expression of HPV5 or HPV8, E6 and E7 (Fig. 3a). Similar findings were obtained in transfected
293 T cells (data not shown). The E7 proteins colocalized with NuMA in interphase nuclei. Manders coefficient for colocalization was $0.45-0.54$ for E6 and $0.78-0.91$ for E7 (Supplementary Fig. 1). Additional weak cytoplasmic staining was shown for the E6 protein. Next, we looked at a possible colocalization of AU1-tagged HPV5 E7 mutants with NuMA. All mutants colocalized with NuMA in the nucleus, comparable to wt E7. Manders coefficient for colocalization was $0.8-0.85$ for the different mutants (Supplementary Fig. 1). This result is in line with the GST pulldown experiments, further reinforcing the notion that interaction with NuMA is not dependent on the pRb binding domain of HPV5 E7.

\section{E7 but not E6 colocalizes with NuMA at mitotic spindle poles}

A central function of NuMA is the alignment and stabilization of microtubules of the mitotic spindle. We therefore studied the localization of E6 and E7 of both HPV5 and HPV8 as well as NuMA in cells undergoing mitosis. AU1-tagged E6 and E7 proteins were expressed in COS-7 cells, and the cells were fixed and further analyzed using 
Fig. 2 NuMA expression in HPV8 positive skin. a Sections of UV-irradiated skin from $\mathrm{FVB} / \mathrm{n}$ wt (top left) and K14-HPV8-CER mice (top right), harvested 24 days after UV treatment, were stained for NuMA. b Representative immunofluorescence staining of NuMA in healthy skin and two individual skin SCC from EV patients positive for HPV5, 8 , 20, 23, 36, 50. c Representative immunofluorescence staining of NuMA in organotypic skin cultures, which were repopulated with PHK harboring the empty retroviral vector $\mathrm{pLXSN}$ (control) or HPV8 E7, respectively, and grown for 14 days at the air-liquid interphase (blue DAPI, green NuMA, dashed line basement-membrane zone, $d$ dermis, $e$ epidermis)
A
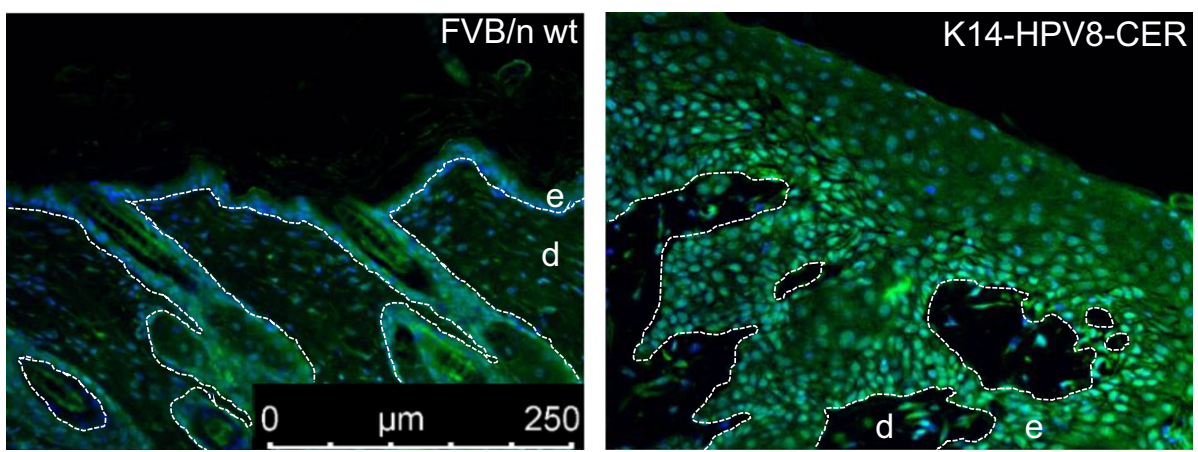

B
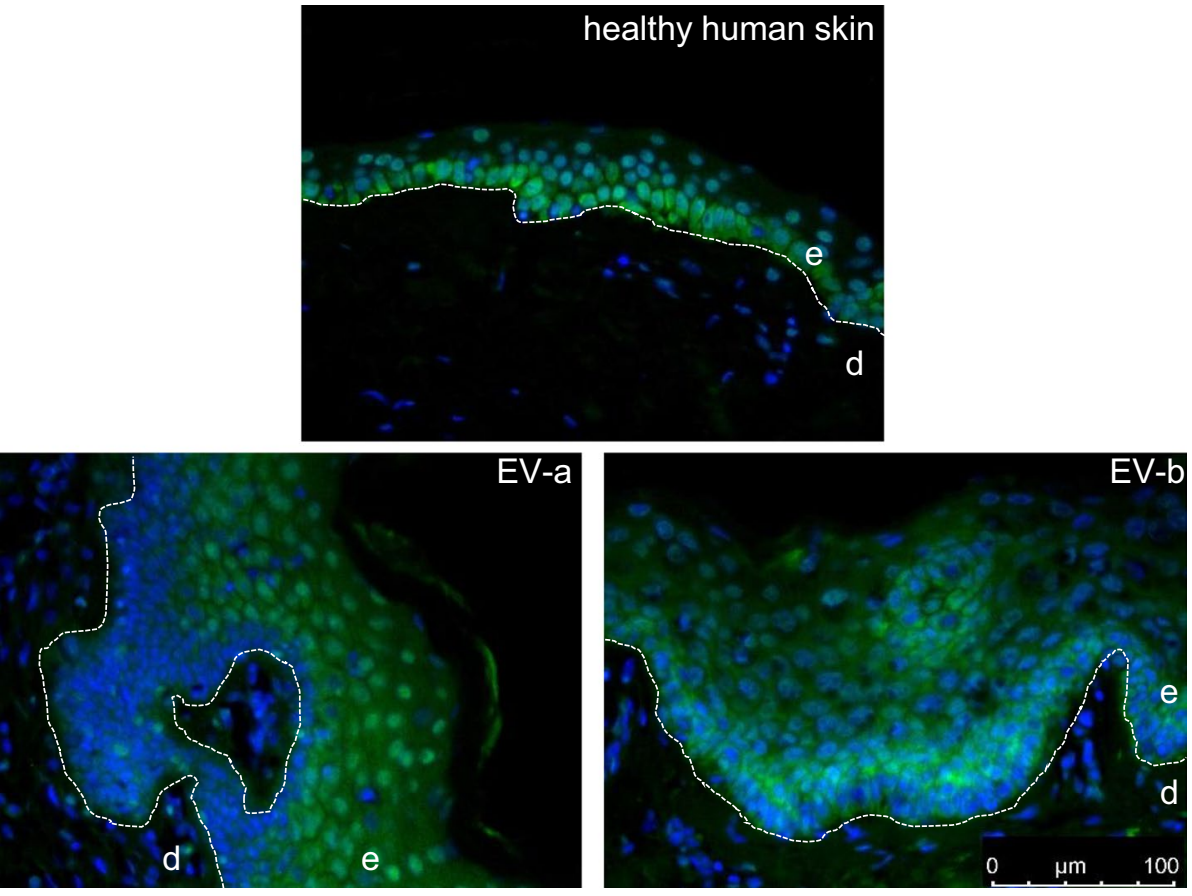

C
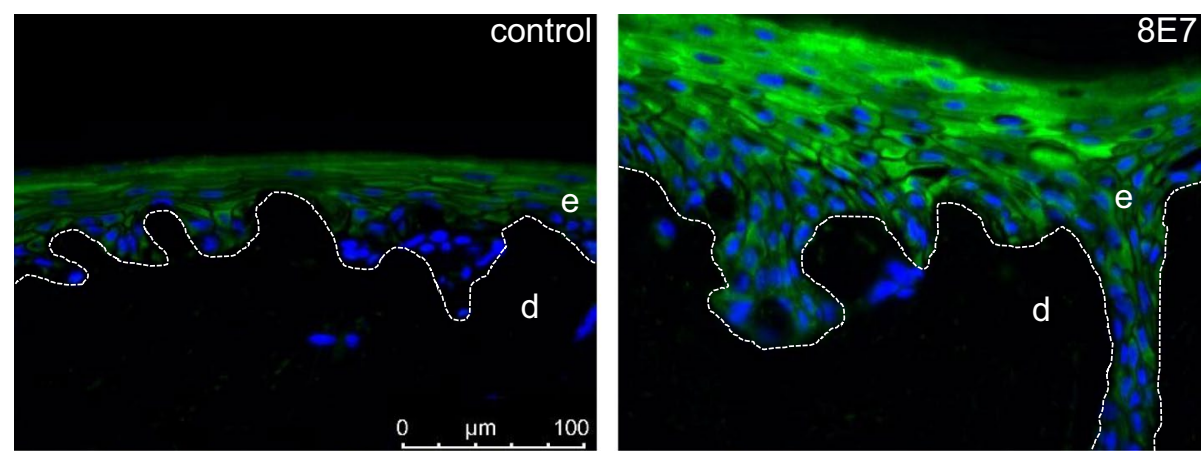

immunofluorescence and laser confocal microscopy. Both HPV5 and HPV8 E7 were found to colocalize with NuMA at spindle poles in mitotic cells (Fig. 3b). Surprisingly, no colocalization of E6 with NuMA was observed during mitosis. Most intriguingly, in a small subset of cells, E7 of both HPV5 and HPV8 was seen at only one spindle pole in dividing cells, whereas NuMA still localized at both poles (Fig. 3b). 
A
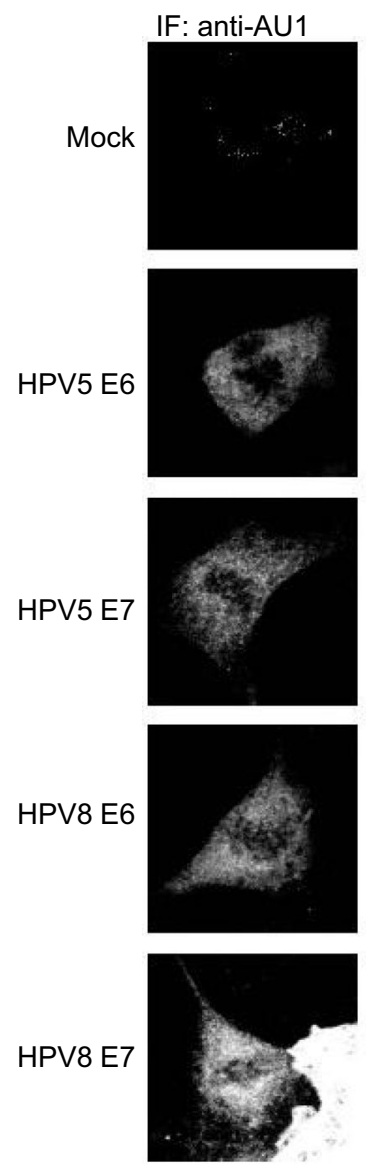
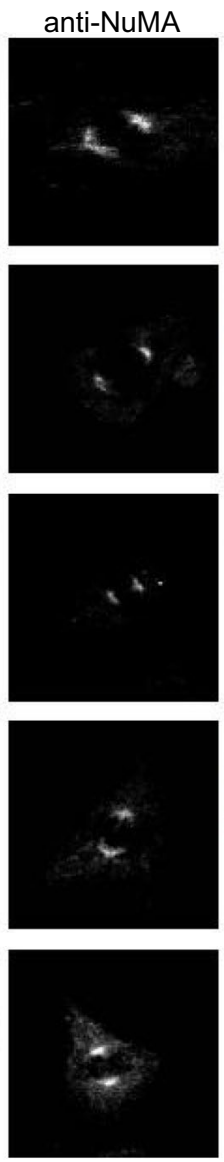
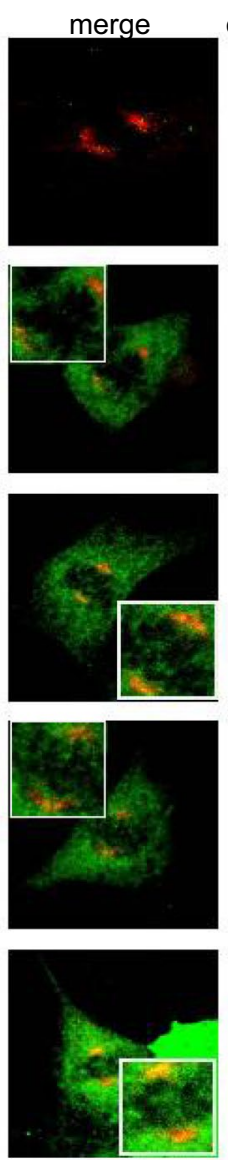

B
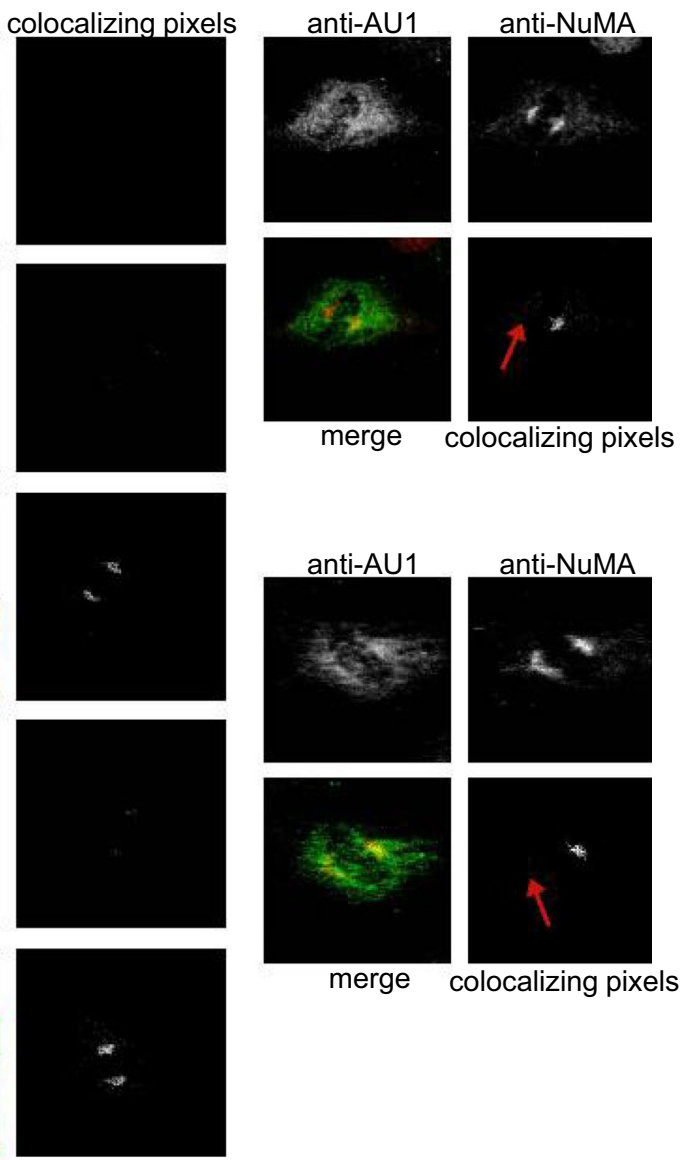

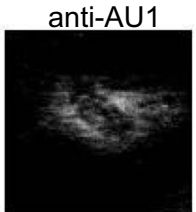

anti-NuMA

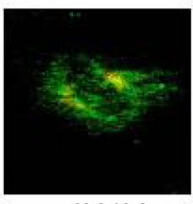

merge colocalizing pixels
Fig. 3 E6 and E7 and NuMA colocalize in interphase. a COS-7 cells were transfected with expression plasmids for HPV5 or HPV8 E6 or E7 provided with AU1 epitope. Fixed cells were stained with antibodies to AU1 (green) or NuMA (red). The images show $z$-axis projections of 15-18 layers. Colocalized pixels were calculated using the Colocalization Highlighter Plugins of ImageJ. Only those pixels which exceeded the cutoff intensity of 100 (8 bit) and whose intensi-

\section{HPV5 or HPV8 E7 do not induce marked aneuploidy}

Based on our observation that E7 and NuMA colocalize in mitotic cells we next asked whether this might interfere with NuMA function during mitosis. In particular, we were interested to see whether the possible interference may impact the stability or lead to misalignment of chromosomes at the mitotic spindle in metaphase. As such associations have previously been described for HPV16 [30-33], we transduced PHK cells with HPV5, HPV8 or with HPV16 E6E7 retroviral constructs for comparison. After undergoing selection, the cells were stained with propidium iodide and analyzed by FACS. No increase in DNA content above $4 \mathrm{~N}$ was observed for any of the different viral proteins (Supplementary Fig. 2a, c). We next treated the transduced PHK cells with nocodazole, a reagent inhibiting polymerization ties on both channels showed at least $95 \%$ correlation were taken into account. b E7 and NuMA colocalize at mitotic spindle poles. Immunofluorescence showing NuMA (red) and AU1-E7 (green) in COS-7 cells expressing either HPV5 or HPV8 E7. The two separate fourfield images show stainings in two individual cells (red arrow: indicates spindle pole without E7)

of microtubuli and causing cell cycle arrest through activation of the spindle checkpoint. The increase in the $>4 \mathrm{~N}$ cell population still remained insignificant, except for HPV16 E6E7, which showed a 5.5-fold increase in the $>4 \mathrm{~N}$ population as compared to empty vector control (Supplementary Fig. 2b, c). Collectively, we conclude that betaHPV E6E7 proteins do not markedly induce aneuploidy in epithelial cells in vitro.

\section{Cell cycle is not altered due to betaHPV E7}

Interaction of HPV16 E7 with NuMA leads to destabilization of the mitotic complex of NuMA with dynein and consequently to chromosomal misalignment in prometaphase. This may in turn result in a prolonged mitosis, as has already been shown for HPV16 in NIH3T3 cells [15]. We therefore 
wanted to explore whether the interaction of betaHPV oncogenes with NuMA may affect the cell cycle in epithelial cells in a similar fashion. To this end, nonsynchronized PHK cells were transduced with pLXSN constructs coding for the different E6E7 proteins. The cells were then incubated with bromouridine, fixed, stained, and examined by FACS analysis. None of the E6E7 proteins disrupted the cell cycle profile to a significant degree (Supplementary Fig. 3a, b). Prolonged prometaphase should have led to an increased cell population in the G2/M phase which was, however, not observed for any of the E6E7 constructs (Supplementary Fig. 3a, b). The experiment was repeated in $293 \mathrm{~T}$ and NIKS cells with comparable results (data not shown). The $>4 \mathrm{~N}$ cell population was only found to be increased in HPV 16 E6E7 expressing cells (Supplementary Fig. 3a, b), which was in line with the results from the nocodazole experiment described above (Supplementary Fig. 2b, c).

\section{BetaHPV E7 does not induce aberrant centrosome distribution}

PHK were transduced with retroviral constructs for E6E7 proteins, fixed, and stained for pericentrin, and the number of centrosomes was counted. HPV5 or HPV8 E6E7 caused minimal changes in centrosome numbers, whereas the changes due to HPV16 E6E7 expression were considerable. We conclude that while HPV16 E6E7 have a strong effect on centrosome duplication, neither HPV5 nor HPV8 E6E7 appears to have this ability (Fig. 4).

\section{A}
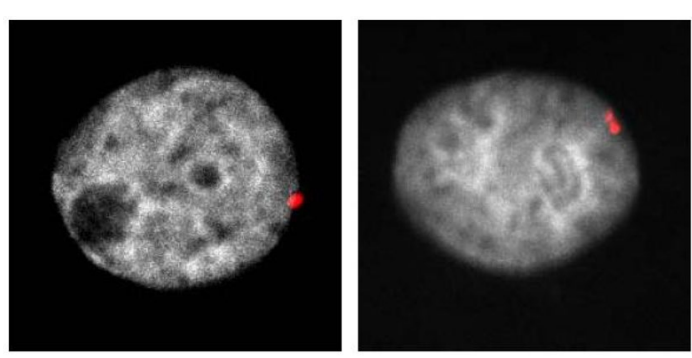

B
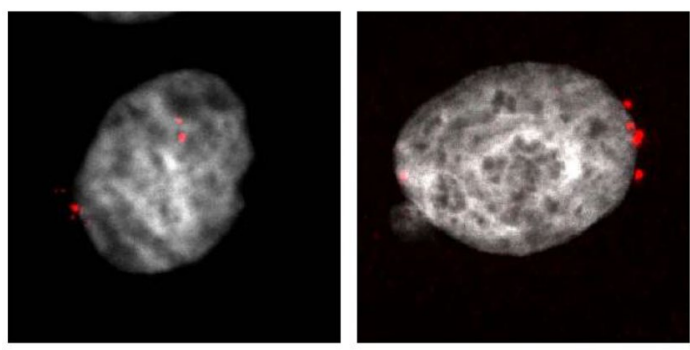

Fig. 4 PHK were transduced with pLXSN vector, or constructs expressing E6 and E7 of either HPV5, HPV8 or HPV16, and the cells were stained for pericentrin (red). a Left image: control; right image: HPV5-E6E7. b Left image: HPV8-E6E7; right image: HPV16-

\section{Discussion}

The role of alphaHPV in cancers at mucosal sites such as the anogenital region and the head and neck region is well established [34]. How betaHPV is involved in skin carcinogenesis is not well understood as betaHPV DNA is less frequently found and is only present in negligible copies per cell in skin cancers. In this respect, a hit-and-run mechanism has been proposed for betaHPV in skin carcinogenesis, a hypothesis which is further supported by experimental models [35-37], suggesting that betaHPV acts as a tumorigenic trigger but is dispensable at later tumor stages. Both alphaHPV and betaHPV exert certain tumorigenic functions. For instance, they both bind pRb [11], which leads to its degradation [12]. Furthermore, it has been shown that HPV16 E7 binds to NuMA, and the binding motif is located within the $\mathrm{pRb}$ binding domain [15]. We now show that betaHPV E7 proteins are also capable of binding NuMA. However, the interacting region does not seem to be located within the $\mathrm{pRb}$ binding domain, contrary to HPV16 E7. In interphase cells, NuMA is a key component of the nuclear matrix, and it is also involved in the reassembly of the nucleus following mitosis (reviewed in [38]). During mitosis, NuMA orchestrates correct organization of microtubules at centrosomes and proper chromosome alignment in preparation of cell division. Contrary to HPV16 E7 [39, 40], only a small proportion of betaHPV E6E7 expressing cells display extra centrosomes, suggesting that there is only a minor interference with centrosome separation upon betaHPV E6E7 binding to

C

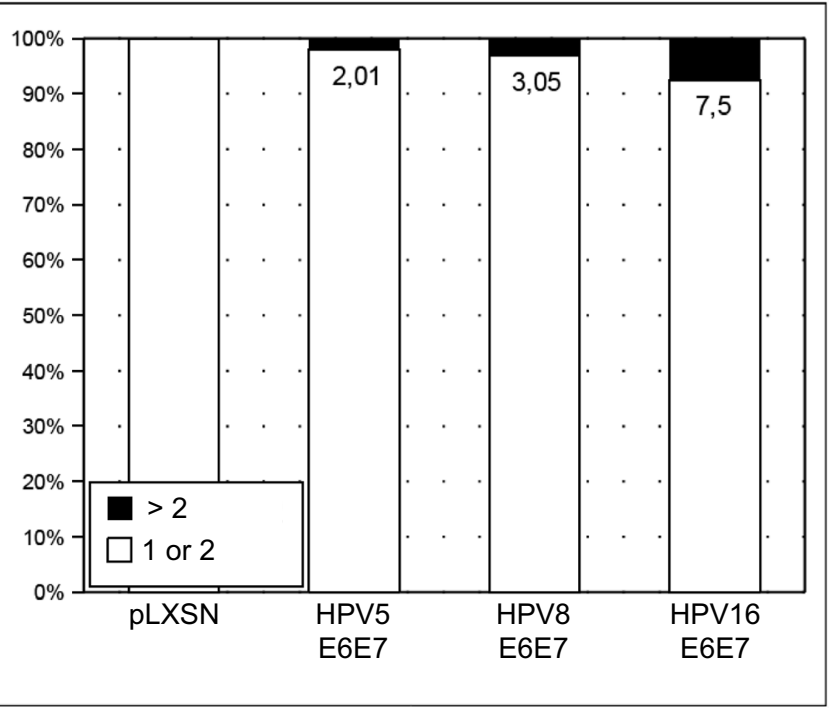

E6E7. c Proportions in percentages of HPV5, HPV8 or HPV16 E6E7 expressing cells with more than two centrosomes. The experiment was repeated twice, and each time 100-200 cells were taken into account 
NuMA. In summary, we report that betaHPV E6E7 binding to NuMA has only a minor effect in respect to cellular DNA content, cell cycle or the number of centrosomes, which has also been shown in the past for HPV16 E7 [41].

Although we did not observe relocalization of NuMA due to betaHPV oncogene binding in 2D tissue cultures, ECM signaling-dependent redistribution of NuMA has previously been shown in carcinogenesis and in differentiation [42]. We therefore analyzed NuMA distribution patterns in the skin of K14-HPV8-CER transgenic mice, in HPV8 positive EV skin SCC, as well as in 3D organotypic skin cultures of HPV8 E7 expressing keratinocytes. In FVB/n wt murine skin as well as skin tumors from transgenic mice, NuMA is located in the nucleus. Unexpectedly, the analyses of SCC skin from different EV patients showed distinct NuMA staining patterns. We observed nuclear localization but, intriguingly, we also found tumors with mainly cytoplasmic NuMA. Curiously, in human 3D skin cultures, which can also be regarded as a wound healing model, NuMA was exclusively cytoplasmic. HPV8 E7 did not affect the distribution, but rather the total expression levels in suprabasal cells. Whether the two distinct NuMA staining patterns are linked to distinct cells of origin of skin SCC [43], or whether wound healing processes may affect the subcellular distribution of NuMA are questions which would most certainly warrant further investigation.

In addition to symmetric cell division, NuMA has an important function in establishing cell polarity required for asymmetric cell division taking place in, e.g., basal epithelial cells, where one daughter cell retains its basal identity, whereas the other cell is committed to differentiation. NuMA is responsible, together with dynein, for positioning the minus ends of microtubules at the poles of the mitotic spindle [44]. A dysfunction of NuMA-dynein complexes may therefore lead to failure in spindle formation and incorrect orientation of metaphase chromosomes. We now show that HPV8 E6E7 proteins bind and colocalize with NuMA in interphase nuclei. However, only E7 associates with NuMA at the poles of the mitotic spindle. It is intriguing that in a small fraction of cells E7 colocalizes with NuMA at only one of the spindle poles. It is tempting to speculate that the asymmetric E7 distribution might alter the proportions of basal or stem cells undergoing asymmetric versus symmetric division in infected skin. Asymmetric basal cell division is a prerequisite for epithelial differentiation, and it enables and supports the completion of the HPV replication cycle. A potential shift of the balance toward symmetric cell division in the basal cell layer would, however, increase the number of stem-like cells, and possibly trigger neoplastic development. We recently provided further support for this idea by showing that particularly the expression of HPV8 E7 in vitro increases the number of stem-like cells in colony-formation and tumor sphere assays, thus facilitating the initiation of oncogenic events, which is also relevant for the hit-andrun hypothesis of betaHPV-mediated skin carcinogenesis [45]. Understanding the molecular basis of NuMA distribution may be relevant for asymmetric/symmetric division in betaHPV-infected epithelia and should be a topic for further research.

Acknowledgements This work was supported by the Canceropole Grand-Est/DKFZ Grant to AA and FA, and by the Finnish Society of Sciences and Letters Grant (EA). MK was supported by the WilhelmSander Stiftung für Krebsforschung (Grant No. 2012.105.3). MH was supported by the Deutsche Krebshilfe (Grant No. 70112727). We thank Dr. Ramon Garcia-Escudero (CIEMAT, Madrid, Spain) for the HPV5 E7 mutant constructs and Professor Slawomir Majewski (Medical University in Warsaw, Poland) for providing EV skin sections.

Author contributions EO, MK, FA, and MH performed the experiments. AA and EA conceived and designed the study. AA, BA, and EA analyzed the data and wrote the manuscript. All authors have read and approved the final manuscript.

\section{Compliance with ethical standards}

Conflict of interest The authors declare that they have no conflict of interest.

Ethical approval Ethical approval for the use of skin biopsies of epidermodysplasia verruciformis patients for scientific purposes was obtained from the Ethics Committee of the Medical University of Warsaw.

Informed consent All authors have reviewed the final version of the manuscript and approve it for publication.

\section{References}

1. Howley PM, Pfister HJ (2015) Beta genus papillomaviruses and skin cancer. Virology 479-480:290-296. https://doi.org/10.1016/j. virol.2015.02.004

2. Smola S (2014) Human papillomaviruses and skin cancer. Adv Exp Med Biol 810:192-207

3. Tommasino M (2017) The biology of beta human papillomaviruses. Virus Res 231:128-138. https://doi.org/10.1016/j.virus res.2016.11.013

4. Bouwes Bavinck JN, Feltkamp MCW, Green AC, Fiocco M, Euvrard S, Harwood CA, Nasir S, Thomson J, Proby CM, Naldi L, Diphoorn JCD, Venturuzzo A, Tessari G, Nindl I, Sampogna F, Abeni D, Neale RE, Goeman JJ, Quint KD, Halk AB, Sneek C, Genders RE, de Koning MNC, Quint WGV, Wieland U, Weissenborn S, Waterboer T, Pawlita M, Pfister H, EPI-HPV-VU-CA Group (2018) Human papillomavirus and posttransplantation cutaneous squamous cell carcinoma: a multicenter, prospective cohort study. Am J Transplant 18(5):1220-1230. https://doi. org/10.1111/ajt.14537

5. Weissenborn SJ, Nindl I, Purdie K, Harwood C, Proby C, Breuer J, Majewski S, Pfister H, Wieland U (2005) Human papillomavirusDNA loads in actinic keratoses exceed those in non-melanoma skin cancers. J Investig Dermatol 125(1):93-97

6. Hasche D, Vinzon SE, Rosl F (2018) Cutaneous papillomaviruses and non-melanoma skin cancer: causal agents or innocent 
bystanders? Front Microbiol 9:874. https://doi.org/10.3389/fmicb .2018.00874

7. Quint KD, Genders RE, de Koning MN, Borgogna C, Gariglio M, Bouwes Bavinck JN, Doorbar J, Feltkamp MC (2015) Human beta-papillomavirus infection and keratinocyte carcinomas. J Pathol 235(2):342-354. https://doi.org/10.1002/path.4425

8. Schaper ID, Marcuzzi GP, Weissenborn SJ, Kasper HU, Dries V, Smyth N, Fuchs P, Pfister H (2005) Development of skin tumors in mice transgenic for early genes of human papillomavirus type 8. Cancer Res 65(4):1394-1400

9. Hufbauer M, Lazic D, Akgül B, Brandsma JL, Pfister H, Weissenborn SJ (2010) Enhanced human papillomavirus type 8 oncogene expression levels are crucial for skin tumorigenesis in transgenic mice. Virology 403(2):128-136. https://doi.org/10.1016/j.virol .2010.04.013

10. Westphal K, Akgül B, Storey A, Nindl I (2009) Cutaneous human papillomavirus E7 type-specific effects on differentiation and proliferation of organotypic skin cultures. Cell Oncol 31(3):213-226. https://doi.org/10.3233/clo-2009-0476

11. Schmitt A, Harry JB, Rapp B, Wettstein FO, Iftner T (1994) Comparison of the properties of the E6 and E7 genes of low- and highrisk cutaneous papillomaviruses reveals strongly transforming and high $\mathrm{Rb}$-binding activity for the $\mathrm{E} 7$ protein of the low-risk human papillomavirus type 1. J Virol 68(11):7051-7059

12. Akgül B, Ghali L, Davies D, Pfister H, Leigh IM, Storey A (2007) HPV8 early genes modulate differentiation and cell cycle of primary human adult keratinocytes. Exp Dermatol 16(7):590-599. https://doi.org/10.1111/j.1600-0625.2007.00569.x

13. Akgül B, Garcia-Escudero R, Ghali L, Pfister HJ, Fuchs PG, Navsaria H, Storey A (2005) The E7 protein of cutaneous human papillomavirus type 8 causes invasion of human keratinocytes into the dermis in organotypic cultures of skin. Cancer Res 65(6):2216-2223

14. Heuser S, Hufbauer M, Steiger J, Marshall J, Sterner-Kock A, Mauch C, Zigrino P, Akgül B (2016) The fibronectin/alpha3beta1 integrin axis serves as molecular basis for keratinocyte invasion induced by betaHPV. Oncogene 35(34):4529-4539. https://doi. org/10.1038/onc.2015.512

15. Nguyen CL, Munger K (2009) Human papillomavirus E7 protein deregulates mitosis via an association with nuclear mitotic apparatus protein 1. J Virol 83(4):1700-1707. https://doi.org/10.1128/ jvi.01971-08

16. Kallajoki M, Harborth J, Weber K, Osborn M (1993) Microinjection of a monoclonal antibody against SPN antigen, now identified by peptide sequences as the NuMA protein, induces micronuclei in PtK2 cells. J Cell Sci 104(Pt 1):139-150

17. Silk AD, Holland AJ, Cleveland DW (2009) Requirements for NuMA in maintenance and establishment of mammalian spindle poles. J Cell Biol 184(5):677-690. https://doi.org/10.1083/ jcb.200810091

18. Iwakiri Y, Kamakura S, Hayase J, Sumimoto H (2013) Interaction of NuMA protein with the kinesin Eg5: its possible role in bipolar spindle assembly and chromosome alignment. Biochem $\mathrm{J}$ 451(2):195-204. https://doi.org/10.1042/bj20121447

19. Maiato H, Pereira AJ (2017) Cell division: NuMA bears the load in the spindle. Curr Biol 27(15):R765-R767. https://doi. org/10.1016/j.cub.2017.06.060

20. Chandramouly G, Abad PC, Knowles DW, Lelievre SA (2007) The control of tissue architecture over nuclear organization is crucial for epithelial cell fate. J Cell Sci 120(Pt 9):1596-1606. https ://doi.org/10.1242/jcs.03439

21. Lechler T, Fuchs E (2005) Asymmetric cell divisions promote stratification and differentiation of mammalian skin. Nature 437:275-280

22. Caldeira S, Zehbe I, Accardi R, Malanchi I, Dong W, Giarre M, de Villiers EM, Filotico R, Boukamp P, Tommasino M (2003) The
E6 and E7 proteins of the cutaneous human papillomavirus type 38 display transforming properties. J Virol 77(3):2195-2206

23. Oswald E, Reinz E, Voit R, Aubin F, Alonso A, Auvinen E (2017) Human papillomavirus type $8 \mathrm{E} 7$ protein binds nuclear myosin $1 \mathrm{c}$ and downregulates the expression of pre-rRNA. Virus Genes 53(6):807-813. https://doi.org/10.1007/s11262-017-1491-6

24. Mendoza JA, Jacob Y, Cassonnet P, Favre M (2006) Human papillomavirus type 5 E6 oncoprotein represses the transforming growth factor beta signaling pathway by binding to SMAD3. J Virol 80(24):12420-12424. https://doi.org/10.1128/jvi.02576-05

25. Sagnia B, Ateba Ndongo F, Ndiang Moyo Tetang S, Ndongo Torimiro J, Cairo C, Domkam I, Agbor G, Mve E, Tocke O, Fouda E, Ouwe Missi Oukem-Boyer O, Colizzi V (2011) Reference values of lymphocyte subsets in healthy, HIV-negative children in Cameroon. Clin Vaccine Immunol 18(5):790-795. https://doi. org/10.1128/cvi.00483-10

26. Heuser S, Hufbauer M, Marx B, Tok A, Majewski S, Pfister H, Akgül B (2016) The levels of epithelial anchor proteins betacatenin and zona occludens-1 are altered by E7 of human papillomaviruses 5 and 8. J Gen Virol 97(2):463-472. https://doi. org/10.1099/jgv.0.000363

27. Buitrago-Perez A, Hachimi M, Duenas M, Lloveras B, Santos A, Holguin A, Duarte B, Santiago JL, Akgül B, Rodriguez-Peralto JL, Storey A, Ribas C, Larcher F, del Rio M, Paramio JM, GarciaEscudero R (2012) A humanized mouse model of HPV-associated pathology driven by E7 expression. PLoS ONE 7(7):e41743. https ://doi.org/10.1371/journal.pone.0041743

28. Sperling T, Oldak M, Walch-Ruckheim B, Wickenhauser C, Doorbar J, Pfister H, Malejczyk M, Majewski S, Keates AC, Smola S (2012) Human papillomavirus type 8 interferes with a novel C/EBPbeta-mediated mechanism of keratinocyte CCL20 chemokine expression and Langerhans cell migration. PLoS Pathog 8(7):e1002833. https://doi.org/10.1371/journal.ppat.1002833

29. Hufbauer M, Cooke J, van der Horst GT, Pfister H, Storey A, Akgül B (2015) Human papillomavirus mediated inhibition of DNA damage sensing and repair drives skin carcinogenesis. Mol Cancer 14(1):183. https://doi.org/10.1186/s12943-015-0453-7

30. Duensing S, Munger K (2002) The human papillomavirus type 16 E6 and E7 oncoproteins independently induce numerical and structural chromosome instability. Cancer Res 62(23):7075-7082

31. Heilman SA, Nordberg JJ, Liu Y, Sluder G, Chen JJ (2009) Abrogation of the postmitotic checkpoint contributes to polyploidization in human papillomavirus E7-expressing cells. J Virol 83(6):2756-2764. https://doi.org/10.1128/jvi.02149-08

32. Patel D, Incassati A, Wang N, McCance DJ (2004) Human papillomavirus type 16 E6 and E7 cause polyploidy in human keratinocytes and up-regulation of G2-M-phase proteins. Cancer Res 64(4):1299-1306

33. Thomas JT, Laimins LA (1998) Human papillomavirus oncoproteins E6 and E7 independently abrogate the mitotic spindle checkpoint. J Virol 72(2):1131-1137

34. Hübbers CU, Akgül B (2015) HPV and cancer of the oral cavity. Virulence 6(3):244-248. https://doi.org/10.1080/21505 594.2014.999570

35. Hasche D, Stephan S, Braspenning-Wesch I, Mikulec J, Niebler M, Grone HJ, Flechtenmacher C, Akgül B, Rösl F, Vinzon SE (2017) The interplay of UV and cutaneous papillomavirus infection in skin cancer development. PLoS Pathog 13(11):e1006723. https://doi.org/10.1371/journal.ppat.1006723

36. Hufbauer M, Akgül B (2017) Molecular mechanisms of human papillomavirus induced skin carcinogenesis. Viruses 9(7):187. https://doi.org/10.3390/v9070187

37. Viarisio D, Muller-Decker K, Accardi R, Robitaille A, Durst M, Beer K, Jansen L, Flechtenmacher C, Bozza M, Harbottle R, Voegele C, Ardin M, Zavadil J, Caldeira S, Gissmann L, Tommasino M (2018) Beta HPV38 oncoproteins act with a hit-and-run 
mechanism in ultraviolet radiation-induced skin carcinogenesis in mice. PLoS Pathog 14(1):e1006783. https://doi.org/10.1371/ journal.ppat.1006783

38. Sun QY, Schatten H (2006) Role of NuMA in vertebrate cells: review of an intriguing multifunctional protein. Front Biosci 11:1137-1146

39. Furuta R, Hirai Y, Katase K, Tate S, Kawaguchi T, Akiyama F, Kato Y, Kumada K, Iwasaka T, Yaegashi N, Kanazawa K, Yoshikawa H, Kitagawa T (2003) Ectopic chromosome around centrosome in metaphase cells as a marker of high-risk human papillomavirus-associated cervical intraepithelial neoplasias. Int J Cancer 106(2):167-171. https://doi.org/10.1002/ijc.11216

40. Duensing S, Duensing A, Flores ER, Do A, Lambert PF, Munger K (2001) Centrosome abnormalities and genomic instability by episomal expression of human papillomavirus type 16 in raft cultures of human keratinocytes. J Virol 75(16):7712-7716. https:// doi.org/10.1128/jvi.75.16.7712-7716.2001

41. Yu Y, Munger K (2012) Human papillomavirus type 16 E7 oncoprotein engages but does not abrogate the mitotic spindle assembly checkpoint. Virology 432(1):120-126. https://doi.org/10.1016/j. virol.2012.06.006

42. Lelievre SA, Weaver VM, Nickerson JA, Larabell CA, Bhaumik A, Petersen OW, Bissell MJ (1998) Tissue phenotype depends on reciprocal interactions between the extracellular matrix and the structural organization of the nucleus. Proc Natl Acad Sci USA 95(25):14711-14716

43. Rodriguez-Paredes M, Bormann F, Raddatz G, Gutekunst J, Lucena-Porcel C, Kohler F, Wurzer E, Schmidt K, Gallinat S, Wenck H, Rowert-Huber J, Denisova E, Feuerbach L, Park J, Brors B, Herpel E, Nindl I, Hofmann TG, Winnefeld M, Lyko F (2018) Methylation profiling identifies two subclasses of squamous cell carcinoma related to distinct cells of origin. Nat Commun 9(1):577. https://doi.org/10.1038/s41467-018-03025-1

44. di Pietro F, Echard A, Morin X (2016) Regulation of mitotic spindle orientation: an integrated view. EMBO Rep 17(8):1106-1130. https://doi.org/10.15252/embr.201642292

45. Hufbauer M, Biddle A, Borgogna C, Gariglio M, Doorbar J, Storey A, Pfister H, Mackenzie I, Akgül B (2013) Expression of betapapillomavirus oncogenes increases the number of keratinocytes with stem cell-like properties. J Virol 87(22):12158-12165. https ://doi.org/10.1128/jvi.01510-13

Publisher's Note Springer Nature remains neutral with regard to jurisdictional claims in published maps and institutional affiliations. 